\title{
Exploring the future of Enterprise Architecture: A Zachman Perspective
}

\author{
Lapalme, James; Gerber, Aurona; Van der Merwe, Alta; Zachman, John; De Vries, Marne; Hinkelmann, Knut.
}

\begin{abstract}
Today, and for the foreseeable future, organizations will face ever-increasing levels of complexity and uncertainty. Many believe that enterprise architecture (EA) will help organizations address such difficult terrain by guiding the design of adaptive and resilient enterprises and their information systems. This paper presents the "Grand Challenges" that we believe will challenge organizations in the future and need to be addressed by enterprise architecture. As a first step in using enterprise architecture as a solution for overcoming identified challenges, the Zachman Enterprise Architecture Framework is used to guide and structure the discussion. The paper presents the "Grand Challenges" and discusses promising theories and models for addressing them. In addition, current advances in the field of enterprise architecture that have begun to address the challenges will be presented. In conclusion, final thoughts on the future of enterprise architecture as a research field and a profession are offered.
\end{abstract}

Keywords - Enterprise Architecture, Enterprise Engineering, Enterprise Information Systems, Grand Challenges

\section{INTRODUCTION}

We live in complex and uncertain times characterized by rapid changes in social structures, operating environments and technology disruptions. At one time, governments were considered to be solid. Today, these once rock-like institutions are recognized as vulnerable because they can be toppled by the winds of social change and market turbulence. Just in the last couple of years countries such as Greece, Italy, Egypt, and Tunisia have been profoundly shaken and as was seen, modern disruptive technologies such as connected social networks have the potential to play key roles in enabling change as well as fostering innovative activities.

The world has become a very challenging place in which to manage organizations. Organizations now face "global markets" that are subject to ongoing social transformation and governmental instabilities. In addition to being affected by turbulence outside of their boundaries, organizations are also faced with the complexities of the changing world within their boundaries. Modern personnel must cope with challenges such as cultural diversity (e.g. plurality of perspectives and values), globalization and disruptive technologies. Today's organizations must "survive" in the modern world where, in the blink of an eye, allies become foes and foes become allies. Moreover, many disruptive technologies are either almost past the "tipping point" of entering the mainstream or lurking on the horizon. Technologies such as Cloud Computing, broadband Always-on-Connectivity, Ubiquitous Computing, 3D printing, etc. could be potential signs of profound yet to come changes in our lives in the same way the television and phone once were [1]-[4]. In summary, the world has become a complex place within which complex organizations (enterprises) operate.

- J. Lapalme is with the Ecole de technologie superieure, CA. Email: james.lapalme@etsmtl.ca

- A. Gerber is with CAIR, Meraka CSIR and the University of Pretoria, SA. Email: agerber@csir.co.za

- A. van Merwe is with the University of Pretoria, SA.Email: Alta.vdm@up.ac.za

- J. A. Zachman is with Zachman International, USA.Email: jazachman@zachman.com

- M. De Vries is with the University of Pretoria,SA. Email: marne.devries@up.ac.za

- K. Hinkelmann is with University of Applied Sciences Northwestern Switzerland Switzerland,SW. Email: knut.hinkelmann@fhnw.ch
Faced with these realities, people concerned with the design and functioning of enterprises must struggle with important questions such as: "How should enterprises cope with pervasive complexity?", "How should enterprise information systems be designed for modern realities?", and "If the realities of today are just the proverbial 'tip of the iceberg' for what is yet to come, how should we prepare?"

Enterprise architecture (EA) is a practice and emerging field intended to improve the management and functioning of complex enterprises and their information systems. Many feel that EA can play a key role in helping to design the enterprises of the future. However, it is difficult not to be inquisitive about how EA will help enterprises face the "realities" of the future or how EA as a technology will itself have to be redefined in order to stay relevant. These are difficult questions to answer since new technologies, and their potential uses, emerge at such staggering rates that it is a difficult process to predict what "Grand Challenges" will emerge.

Enterprise information systems are a key component of an enterprise's architecture. Implementing and changing an enterprise information system entails that its architecture will change. Conversely, any change to enterprise's architecture will have repercussions on its information systems. Consequently, next generation enterprise information systems should be seen in the context of these new realities.

The reflections of this paper are guided by the Zachman Framework for Enterprise Architecture (ZFEA), a wellrecognized EA model that offers an ontology for enterprises [5]. Through the use of the ZFEA, we propose a number of "Grand Challenges" that we foresee to be important for the design of enterprises and their information systems. We also discuss useful models and theories that we believe could be useful in coping with the identified "Grand Challenges". In order to exemplify the value of these models and theories, we discuss current advances in the field of EA that are guided by the presented models and theories. It is not the intention of this article to analyze in detail the "Grand Challenges" with various EA tools (e.g. models, frameworks, etc.) but rather to explore how EA is evolving (and should 
evolve) in order to stay relevant with regards to the "Grand Challenges". Towards this purpose we found the Zachman Framework for EA valuable to guide the discussion about directing the use of EA to help enterprises of today reflect upon the future and themselves.

The article is organized as follows. In section 2, we briefly introduce the field and practice of EA as well as discuss its relationship to EE and enterprise information systems (EIS). In section 3, we present the ZFEA as well as the results of using it to foresee the challenges of the future. Subsequently, these challenges are synthesized into four "Grand Challenges" that serve as the focus for the rest of the paper. In section 4, we present for each "Grand Challenge", useful models and theories for coping as well as recent advances in the field that are either guided by these theories and models or other closely related literature. Section 5 discusses possible future scenarios for the practice and investigation of EA.

\section{Contribution To NeXt Generation ENTERPRISE INFORMATION SYSTEMS}

\subsection{Enterprises, Enterprise Frameworks, EA and EE}

The initial idea to describe, understand, represent and design different dimensions of the enterprise was developed simultaneously within different disciplines in the early nineties. This lead inevitably to the emergence of several EA frameworks [6]. One of the original frameworks was the Zachman Framework for Enterprise Architecture (ZFEA) [7] that has as purpose the identification of the basic elements that an enterprise comprise of. Many existing EA frameworks were inspired by the ZFEA such as the Extended Enterprise Architecture Framework (E2AF), Enterprise Architecture Planning (EAP), Federal Enterprise Architecture Framework (FEAF) and the Integrated Architecture Framework (IAF) [6].

Initially the Industrial Engineering community and the manufacturing sector proposed several EA initiatives and frameworks. One of these initiatives was an international study that raised awareness about the emerging engineering discipline within enterprise integration in 1992 [8]. During 1989-1992 research at the Purdue Laboratory for Applied Industrial Control (PLAIC) led to the development of the Purdue Enterprise Reference Architecture (PERA) to address the complexities of industrial enterprises, emphasising the human involvement within the enterprise system [6], [9]. The Computer Integrated Manufacturing Open System Architecture (CIMOSA) association was established in 1994 to develop an open system architecture to set standards and facilitate the development of future CIM systems [6], [10]. During the 1990's the Federation of Automatic Control (IFAC) and International Federation for Information Processing (IFIP) created a task force to evaluate the existing frameworks, which led to the development of the Generalised Enterprise Reference Architecture and Methodology (GERAM) [11]. During the same time frame, Doumeinghts et al. also developed the GRAI Integrated Methodology (GIM) for designing CIM systems, which was later mapped onto GERAM [11], [12].

Given this history there are numerous views on what EA is. For the purpose of the paper, in order to stay neutral, we prefer to use a definition of EA that is broad and inclusive. We thus propose a definition that builds upon the ISO/IEC/IEEE 42010 standard [13] namely that EA should be understood as constituting of the essential elements of a socio-technical organization, their relationships to each other and to their changing environment as well as the principles of its design and evolution. Enterprise architecture management is the continuous practice of describing and updating the EA in order to understand complexity and manage change. This definition should be understood just a means to facilitate the understanding of this paper. This is only one definition of EA and at present there are a number of core definitions used, as well as several prominent discussions about the meaning of general terms within the EA domain [14], [15]. The reason for the existence of multiple definitions is arguably, as mentioned, the input that the domain receives input from several associated domains and disciplines such as systems engineering, organizational science, industrial engineering, and last, but not least information systems and ICT. Each of these disciplines place a unique perspective on the notion of enterprises and what we need to do to align, design, engineer or change them [16]. A number of other more specific definitions and discussion on the meaning of EA may be found in [13], [14], [17]-[22]. Enterprise engineering (EE) and enterprise ontology (EO) are terms that emerged within the enterprise and EA domains [23]. EE developed as a sub-discipline from the systems engineering domain, which means that it is largely practicebased and aims to study enterprises in a multi-disciplinary and engineering-driven way [24]. EE inherits concepts from systems engineering, including the definition of enterprises as socio-technical systems, but also the notion that within enterprises, it is possible to distinguish between teleological and ontological systems [25]. According to Dietz [25], an EO describes the construction and operation of a system and is therefore needed to design the enterprise [26]. For the purpose of this paper, since consensus on the meaning of terms such as EA and EE doesn't exist within the community, we will mainly consider the term EA and adopt its meaning to be as comprehensive as possible and since the focus of this paper is on the design of the enterprise of tomorrow, ambiguity with the meaning of EA and EE is of little concern. We choose to be inclusive and adopt all different perspectives as part of the discussion about enterprises and their future.

\subsection{Relationship with and Contribution to EIS}

Enterprise Information Systems (EIS) are defined as all the information systems (composed of people and technology) that support the integrated functions of an enterprise. However, the field of EIS nowadays also encompasses all aspects related to such systems, including the design, implementation, deployment, maintenance and acceptance thereof [27]. Enterprise architecture often provides the context for enterprise information systems, and depending on the enterprise view adopted, EA would influence or prescribe the requirements, design and implementation of the enterprise's EIS [18].

Given the above synergy between EIS and EA, the identified "Grand Challenges" for future EA, as well as the reflec- 
tions about society, technology and directions of future theory, will inform the future of EIS as the IS realizations of enterprises.

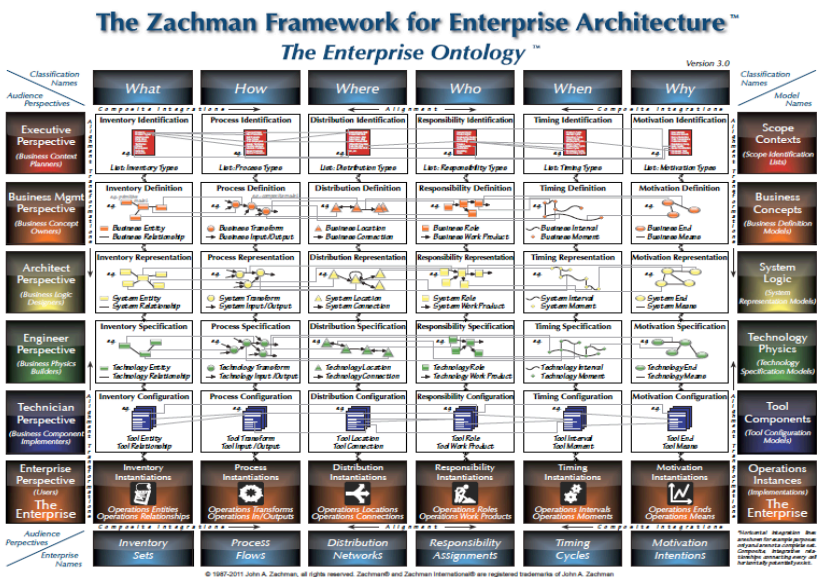

Figure 1: The Zachman Framework ${ }^{\mathrm{TM}}$ [28]

\section{BACKGROUND}

\subsection{Zachman Framework Overview}

Zachman calls the Zachman Framework for Enterprise Architecture or Zachman Framework'TM (ZFEA) 'The Enterprise Ontology' or the theory of existence of components of an enterprise [28]. Zachman also describes the ZFEA as a schema because it represents the intersection between two historical classifications that have been in use for thousands of years [29]. The ZFEA depicted in Figure 1, is a $6 \times 6$ bounded matrix where the columns depict the fundamentals of communication or primitive interrogatives namely What, How, When, Who, Where and Why. The rows represent the notion of reification - the transformation of an abstract concept into an instantiation through different design perspectives [30]. One common misconception of the rows is that lower rows are refinements of upper rows, or that lower rows provide a more detailed description of upper rows. This is not true since each row represents all the models of the enterprise from a specific perspective, and there may be different levels of detail within a particular row.

The intersection between the Interrogatives and the Transformations in the ZFEA are the framework classifications and primitive elements. Each cell in the ZFEA is a normalized fact (or a primitive) so that no one fact can show up in more than one cell. According to Zachman, the complete matrix would necessarily constitute the total set of descriptive representations that are relevant for describing an enterprise [28]. In order to construct meaningful models of any enterprise, it is necessary to combine primitives. In general, EA models are combinations or composites of the basic primitives and logic in the ZFEA and from the primitive cells all composite models that describe the enterprise could be constructed by combining model primitives in rows [31]. The architecture of an enterprise is the total set of intersections between the abstractions and the perspectives and the enterprise itself is the implementation, depicted in the framework as row six.

\subsubsection{Zachman Interrogatives}

Zachman specified that the columns in the ZFEA are the fundamentals of communication namely What, How, When, Who, Where and Why and the answers to these interrogatives will allow an engineer to describe all aspects of any engineering object [28]. For the ZFEA Zachman specifically defines what the interrogatives would imply within the context of enterprises, namely that the What interrogative translates into Inventory Sets, the How into Process Flows, the Where into Distribution Networks, the Who into Responsibility Assignments, the When into Timing Cycles, and the Why into Motivation Intentions. In order to allow for a comprehensive description of the enterprise, the Zachman interrogatives are combined with the Zachman perspectives described in the next section.

\subsubsection{Zachman Perspectives}

The rows in the ZFEA represent different perspectives on the enterprise from the viewpoint of different stakeholders. The Executive Perspective row represents the perspective of an executive, possibly the board of directors or the executive management concerned with the position of the identified enterprise within its operating domain. This view is not concerned about any technology that supports its operations and would only consider technology if it has an impact on its positioning, or when it is something that might provide a competitive edge.

The Business Management row represents the perspective of business management, typically the managing director or the CEO of the enterprise. This perspective is concerned with the business itself, and would typically transform/translate/reify the perspective of the executive into the business model.

The Architecture row represents the perspective of the business architect. This perspective is interested in the logical building blocks necessary for the enterprise to operate and would take the perspective of the business owners or the business model and translate / transform (or reify) these into the enterprise building blocks. Technology that supports the business model would feature in this perspective, where components such as a customer database or a workflow system are building blocks. In this perspective, business-IT alignment would be a concern, specifically if IT is a technology of choice.

The Engineer row represents the perspective of the enterprise engineers interested in 'building' or designing the building blocks identified by the architecture. This perspective would translate, transform (or reify) the enterprise building blocks into system constructional requirements and specifications for building the systems.

The Technician row represents the perspective of the business technicians such as the database implementers and the workflow system implementers. This perspective implements the constructional designs of the previous perspective. It would, for example, translate the database schema of the customer database into SQL statements for a relational database server.

The Enterprise row represents the perspective of the running enterprise, i.e. the physical enterprise offices with a physical address that a customer would enter, a server room 
and a backup system for the customer database system.

\subsection{Foresight with Zachman}

Maier [32] argued that the act of architecting is very much about structuring ill-defined problems. Similarly, Charles Kettering is known to have said: a problem well stated is half-solved. We would argue that attempting to foresee the "Grand Challenges" that will face the discipline of EA is quite an ill-defined problem. As architects, we used a tool of our trade to bring structure to our foresight endeavor. We thus used the ZFEA to frame the problem at hand and to help guide our inquiry.

A key challenge in attempting to foresee how a "complex thing" will change is to approach the problem systematically, to consider all the dimensions thereof. The Interrogatives and the Perspectives of the ZFEA, as such, offer a systematic means for identifying the various dimensions of an enterprise (i.e. a complex thing) that can change. As stated previously, EA is concerned with designing enterprises, which are man-made artifacts. Consequently, by using the ZFEA to systematically contemplate how enterprises could change in the future, we would argue that it is possible to attempt to foresee the challenges that architects will face when they design these enterprises of the future. Many other frameworks or models could have been used. The rational for having only used one framework and for having selecting more specifically the ZFEA is that it is regarded as one of the fundamental 'ontologies' representing the essential structural nature of enterprises. Space limitations prohibit this paper to include multiple frameworks. Despite its simplicity, the ZFEA is an effective and intuitive tool to use to think holistically about enterprises.

The way we used the ZFEA for guiding our reflection is as follows: each row and each column were use independently as a means for generating ideas and reflecting about how enterprises could change in the future and what challenges they will face based on our current knowledge. We used the ZFEA as a means for structuring a focused discussion group activity with diverse participants from various countries and disciplines. Once our suggested list of ideas was saturated, we collectively synthesized and consolidated the various ideas into three "Grand Challenges" that served as the core of the paper. Given that the focus of the paper is about discussing a small number of key "Grand challenges" and not to identify enterprise architecture solutions for each possible challenge, we didn't analyze to the level of the ZFEA cell.

What follows is a summary of the results from our focused discussion group activity. In accordance to how our activity was structured, each one of the columns and rows is discussed separately, followed by our synthesis.

\subsubsection{What Interrogative}

The "What" Interrogative is about the set of "things" (inventories) that enterprises must track, manage and which may have multiple uses: input/output of transformation processes, input/output of decision-making processes, means for execution transformation or decision-makings process.

In future these inventory sets may change rapidly and even not be under complete control of the enterprise. One such inventory set is enterprise data. Through technologies such as the Internet, organizations have access to vast amounts of data about anything and everything that can be used for producing useful information.

Traditionally, organizations were concerned with using and managing the data that were under their control, within their boundaries. Today, and for the foreseeable future, shifts are occurring in which key data that are utilized by organizations reside and evolve outside of its boundaries. We have already reached the point where there are more data outside the boundaries of organizations than within. Technologies related to big data, the Cloud, the Internet-ofThings and pervasive data are illustrative of this unfolding.

In the future, organizations will have to adapt quickly with regards to utilizing data outside and within their boundaries. Moreover, they will have to go beyond just understanding each datum in isolation but be capable of looking across data sets, integrating them in order to gain information from the web of relations that connects data items. In short, organizations will be faced with the challenges of being effective at making sense of (and acting accordingly) unprecedented amounts of data.

Another inventory set that traditionally was completely under control of enterprises is human resources. It is acknowledged that one of the models of future skills sets would be acquisition-as-needed implying that the management of the enterprise knowledge, intellectual property and skill sets will pose completely new challenges.

\subsubsection{How Interrogative}

The "How" Interrogative is concerned with how work and processes are designed and executed within the enterprise. As mentioned in future enterprises will have to be capable of coping with increased complexity. We would venture further and add high levels of uncertainty due to rapidly changing operating environments. Consequently, adaptability with regards to how work is executed within the enterprise will be a requisite organizational capacity for survival.

One of the main sources of organizational adaptability and innovation lies within people. People execute the work and processes within the enterprise and people would therefore be the main agents that deal with complexity and uncertainty. Hence, organizations will have to design work and processes that are human-centric and that are meaningful for workers, as well as allow them to deal with complexity and uncertainty. Such designs are at the opposite of those that privilege standardization and compliance; hence making them suitable for machines but unfit for people. In addition, as world resources decline, enterprises will have to design processes that respect people, society and the environment and use scarce resources in a sustainable manner.

Organizations will be faced with the challenges of designing enterprises according to non-traditional paradigms (e.g. Tayloristic Models and Scientific Management).

\subsubsection{Who Interrogative}

The "Who" Interrogative is about organizational stakeholders as well as their respective roles and responsibilities.

A contributing factor to the increase of complexity within 
organizations is the increasing heterogeneity of work forces. Present trends, that we believe will continue for the foreseeable future, include more as well as less educated workers (as a result of the increased digital divide), work professionalization, increasing number of retirees, and increasing as well as rapidly changing workforce with cultural and generation diversity.

Organizations could be faced with significant challenges with regards to power, ownership, roles and responsibility. With the advent of coproduction and co-creation [33],[34], hence integrating clients as active participants in production and ideation processes, the demarcation between employees and clients will continue to blur. With the increasing capacity of external stakeholders (e.g. clients) to organize themselves, the scope of powerful stakeholders will include the average person and not just large public and private sectors organizations. Moreover, combined with globalization, stakeholders will emerge from across the globe and will demand that their social and ecological concerns be considered.

\subsubsection{Where and When Interrogatives}

The "Where" and "When" Interrogative are about changes with regards to space (i.e. location and distance) and time.

Traditionally, organizations were clearly established in precise geographic locations and time zones. With the advent of globalization, modern organizations can span the globe both in terms of targeted clients, production locations and operating hours. Modern ICT technologies create the possibility of enterprises being purely virtual organizations, organizations that exist only electronically, as well as enterprises that potentially exist everywhere and are never closed.

Consequently, virtuality, always available and boundaryless could become common enterprise characteristics and their respective challenges common day-to-day issues.

\subsubsection{Why Interrogative}

The "Why" Interrogative is about intentions and values, the motivations that drives organizational behaviors, decision-making and concerns.

Over the years we have witnessed an increase in awareness in understanding and in expectations within the general population with regards to wealth distribution, missmanagement of natural resources and the ill treatment of low-income labor. Resources are becoming scarcer and there is a growing realization that all actions have consequences often across country or continental boundaries. For example, the irresponsible use of rain forests in a remote location on earth has an impact on global climate change. Many enterprises had to respond to these concerns by using processes and providing goods and services that are either ecological or ethical or socially responsible or a combination. Underlying this shift is a transformation in intentions; enterprises are beginning to operate according to intentions that go beyond just immediate financial gains. Enterprises will have to face challenges of designing themselves in such a way that they can effectively and sustainably address their triple-bottom line: social, environment and financial concerns.

\subsubsection{Executive Perspective}

The "Executive" perspective is mostly externally fo- cused. The executive of the future will be faced with the challenges of guiding their enterprises through a world full of complexity and uncertainty. In such conditions, current ways of doing would probably lead to failure [35].

Illustrative of these challenges will be to navigate the terrain of turbulent socio-economical markets, to deal with quick and sudden shifts in market trend and technologies, and to manage boundary-less customers, partners and competitors.

Executives of the future will have to be able to establish the "right" partnerships and build the success of their organizations on inter-organizational trust and openness because isolation will lead to failure [36].

\subsubsection{Business Management Perspective.}

The "Business Management" perspective is primarily internally focused. The mangers of the future, similarly to executive, will be faced with the challenges of guiding their work forces. As already stated, the complexity and uncertainty within organizations will reflect the complexity and uncertainty of their environment. Asbhy's Law of Requisite Variety states that "variety can destroy variety" [37]. Consequently, the mangers of the future will have to strive to foster organizations with immense variety. However, such levels of variety will necessary bring into question current organizations structure and management practices that are focus on achieving stability, conformance and standardization.

In addition, the management of enterprise knowledge and required human skill and expertise will be key for the future in order to achieve high levels of organizational variety.

\subsubsection{Architecture Perspective}

The "Architecture" perspective is primarily concerned with understanding the components of the enterprise and the relationships between them.

In the context of high levels of complexity and uncertainty, the notion of causality often breaks down. Often, one can only assume that everything is in relationship with everything else. Consequently, often, understanding the ramifications of changes such as disruptive technologies and new architecture models (i.e. cloud computing, out-sourcing), is almost impossible. New resources such as contextual data of customers will have to be used effectively to gain a competitive edge. In order to face such challenges, the notion of architecting will surely have to be redefined. It has been proposed that future architecture is about structuring the ill defined, or about acknowledging that you 'will not get it right, but you need to get it as close as possible'[38]. More emphasis will possibly be on prediction and scenario analysis as tools for architecting.

\subsubsection{Engineer Perspective}

The "Engineer" perspective is concerned with designing all aspects of the enterprise. Traditional approaches to designing are based on the assumptions that problems can be clearly formulated and that appropriate methods can be identified for solving these problems. The designs also assumed control over resources. Moreover, in the past, it was often possible to design organization in ways that were very structured in order to achieve predictable efficiency.

In the future, the challenges of designing organizations 
will possibly revolve around never completely understanding the problem statement nor ever reaching a final design or answer. Designs have to take into account that enterprises may not necessarily control resources. Enterprises may be in a constant state of design in order to stay relevant and agile, and will have to design for redundancy that may use resources from more than one source and with varying levels of control, consistency and reliability. The dreaded 'change in scope' of any project will possibly be the norm.

\subsubsection{Technician Perspective}

The "Technician" perspective is concerned with execution. The key challenge with execution in the context of future organizations will be with regards to coping with "rules of engagement" that are always changing. Key concerns such as skill sets, performance expectations, organizational structures and enterprise knowledge will be constantly changing in order to adapt to complexity and uncertainty within and outside organizations.

\subsection{Synthesis of Challenges}

We summarize the different challenges that were discussed in the previous section into three overarching "Grand Challenges" as follows:

1. Increased complexity and uncertainty: The design of enterprises that is resilient to increasing complexity and uncertainty. Some of the key questions include "How do we do enterprise architecture in the context of increasing complexity?" and "How do we do enterprise architecture when we can no longer act "as if" we can understand the "whole picture and predict the future?"

2. New realities: The design of enterprises in the context of new "realities". Some of the key questions include "how do we design non-traditional organizations?", "how does enterprises take into consideration the new realities such as virtual and connected organizations, a population and work force that spans cultures and generations?" and "How do we achieve socially and environmentally responsible, humane EA that focus on creating systems for smart people?".

3. Evolving Enterprise Architecting: The redefinition of architecting and engineering enterprises. Key questions under this challenge include "how must enterprise architecture and engineering redefine themselves as the meaning of 'enterprises' and 'designing enterprises' changes?"

\section{Coping With THE GRAND Challenges}

Within this section we present each "Grand Challenge" and some relevant theories, models, languages, tools that can help to address it. This section will offer a non-exhaustive account of some of the contributions that have been made to address the "Grand Challenges".

\subsection{Architecting enterprises for complexity and uncertainty.}

The concept of complexity has been explored in many different disciplines; hence multiple definitions exist. In the context of EA, complexity involves coping with situations that are either very difficult or utterly impossible to comprehend in their entirety [39]. When faced with complex situations, it is seldom possible to be certain that all key aspects of the situation have been considered; hence making it very difficult (if not impossible) to contemplate the causal relations related to the situations. This unavoidably leads to uncertainty.

When designing systems, a shift of intent should be made from 'designing in order to define an optimal solution' to 'designing in order to build capacity within the system to constantly adapt'. The first intent is one of ends, while the second is one of means.

A key means for building adaptation capacity is empowerment. Beyond recognizing the humanity and value of people and teams, giving people the opportunity to make the right decisions at the organizational level at which awareness of the context is the highest, offer the best opportunities to cope with complexity and uncertainty. However, in order to cope with complexity and uncertainty, coordinated decision-making and acting is key, which is at the opposite of parochialism and reductionism. Such modes of thinking and acting will require stakeholders, such as workers, to recognize that they are part of a larger context.

Associated with building capacity for adaption, is building capacity for change, especially within organizations. Workers will need assistance to cope with constant and sometimes dramatics changes within the enterprise. Organizations as a whole will have to become effective at implementing changes at all levels and of all magnitudes.

A significant number of theories and models are available that relate to designing systems and decision-making in the context of complexity and uncertainty. Some of the related theories, but by no means the only or the most important, are Complex Adaptive Systems (CAS) [40], Cynefin [41], High Reliable Organizations (HROs), Systems Thinking [42], and Open Systems Theory (OST) [43].

CAS and Cynefin are related to the study of complexity. CAS are self-organizing systems that exhibit emerging properties and behaviors, and that are capable of adapting to changing environments. Cynefin is a framework that offers a typology of complexity domains (i.e. Obvious, Complicated, Complex, Chaotic and Disorder). The model identifies what types of explanations and solutions are appropriate per domain. Based on the concepts of complexity science, a number of contributions have been made. Rebovich and White [44] present advances in the field of enterprise systems engineering (ESE), which is an extension of traditional systems engineering (SE) theory and practice where the enterprise is the system. Due to technological advances, the scope of ESE necessarily extend beyond the bounds of a single system and include systems that exhibit organized complexity [44]. Graves [45] presents an EA modeling approach based on Cynefin. Graves [46] claims that EA should not focus on IT, but should be about the architecture or structure of the whole enterprise and everything the enterprise is and does. He proposes what he calls a 'systematic' approach driven by enterprise perspectives generated by combining the 5Ps (Purpose, People, Preparation, Process and Performance) with 5 enterprise views (Efficient, Reliable, Elegant, Appropriate and Integrated). In Pallab [47], multiple authors 
discuss complexity management in the context of EA.

The concept of HROs as well as the theories and practices of OST are concerned with adaptive organizations. HROs focus on the concepts of sense-making and organizational mindfulness for achieving organizational resilience. OST offer insight and practices for designing and implementing participative and democratic organizations based on selforganizing teams. Hoogervorst [22] suggests an organismic approach to design and govern the enterprise that "is directed to adaptation, flexibility and the ability to change in light of unforeseen requirements". Moreover, the approah promotes bottom-up empowerment and governance as well as emphasises employee competencies.

As described by Jackson [48],[42], there are multiple streams of systems thinking (i.e. Hard Systems, Dynamic Systems, Soft System, Emancipatory and Postmodern). Each stream has it own assumptions about how to address issues of complexity, power and subjectivity. Consequently each stream can provide insights for coping with complexity and uncertainty. The Viable System Model (VSM) [49] has been fairly influential; in [50], multiple authors discuss how the concepts of VSM can be used for analyzing and guiding the design of enterprises. Other streams, such as Systems Dynamics [51], have been used for analyzing the complex relationships between enterprises in the wider context [39]. Based on OST and the ideals of democratic (participative) organization that it promotes, Lapalme and de Guerre [52] have defined principles for conducting EA.

Zachman proposes another view on engineering complex enterprises, which is mass customization or 'assemble to order'. After identifying the primitive models that represent the enterprise, the enterprise engineers could design the enterprise by combining primitives as required [53], [54].

\subsection{Architecting enterprises for the new realities}

How new realities shape enterprises can be seen in statistics such as the lifespans of companies on the Standard \& Poor's 500, which has seen a threefold decrease from more than 60 to less than 20 years since 1960 [38], [55]. Add to these statistics Moore's law that predicts that the overall processing power for computers will double every two years and enterprises of the future will need to accommodate new realities in order to survive.

For the purpose of this discussion, we collected some insights from forecasts and futurists that forecast a future with an aging population in the developed world but a younger population in the developing world, a world where the divide between the haves and have-nots increase with regards to both wealth and power, and basic commodities like clean water and air are scarce and expensive for large numbers of people, but where unexpectedly, people rise above limitations and could cross boundaries due to access to technology [56]. This means that an enterprise may unexpectedly have a work force or customer base that spans not only generations and cultures, but also possibly very different economic realities.

Enterprises and the supply chains they participate in, beyond the challenges of globalization, must cope with the new realities of social and ecological responsibly. Hence, in the future, designing triple botton-line focused enterprises (and extended enterprises) might not be an option but an obligation in order to ensure sustainability. In essence, striving for the triple bottom-line enterprise is about fostering sustainable enterprises from the perspectives of all their stakeholders, their environments and their financial viability. From the perspective of people, such enterprises is about fostering healthy and humane workplaces that value worker self-actualization and healthy communities [39]. Empowering people is a key means for recognizing the humanity of people as well as their value. The pursuit of sustainable enterprises from the perspective environment is necessarily about fostering enterprises that are capable of staying in a healthy bi-directional relationship with their environment. Such enterprises are capable of adapting to change in their environment as well as capable of contributing to the health of their environment. This is at the opposite of enterprises that exploit their environments financially, socially or environmentally.

There are a significant number of theories and models available that can be useful for guiding EA within the context of "the new realities". Some of the theories and models mentioned previously would be relevant such as CAS, ST and OST. In addition, the Human-Tech Ladder [57], Critical Systems Heuristics [58] and Biocomplexity [59] can be helpful.

OST and the Human-Tech ladder are both concerned with the systemic relationship between people and technologies The Human-Tech ladder offers a model composed of five levels (i.e. physical, psychological, team, organizational, and political) that help guide the design of socio-technical systems. OST provides theories for designing systems-inenvironment (i.e. open socio-technical systems) and guiding their evolution. Critical Systems Heuristics fits within the emancipatory systems thinking stream. It offers practical guidelines for critically approaching systems design and planning in the context of power and the diversity of intentions.

Biocomplexity is a field of research that studies the properties emerging from the interplay of behavioral, biological, chemical, physical and social interactions that affect, sustain, or are modified by living organisms, including humans [59]. It can offer insights when considering enterprises and their impact of society and the environment.

From a more organizational science perspective, advances with regards to the concepts of virtual and boundaryless organizations will be useful in coping with the implications of globalisation, networked-oriented organizations and coproduction [60],[34].

Guided by various systems thinking streams, some authors have proposed EA approaches that strive to go beyond strictly financial concerns. Villarreal [39], guided by systems-dynamics, has developed an analytical framework for considering key sustainable development concerns (eg. poverty, ecology, etc.). Lapalme and de Guerre [21], guided by OST, have proposed key principles for undertaking EA in a manner that is both humane and fosters enterprise-inenvironment coevolution. Guided by similar influences, Laverdure and Conn [61] have combined a number of system thinking streams for addressing sustainability concerns. Villarreal [39] offer an analytical framework for combining 
sustainable development and EA concerns.

\subsection{Evolving the meaning of enterprise architecture}

Traditionally, the field of EA has been focused on achieving business-IT alignment or ensuring that IT aligns with and supports the business strategy. This tradition, strongly influenced by the fields of engineering and computer science, was underpinned by a number of assumptions that guided problem solving. Some of the key assumptions were reductionism (i.e. divide-and-conquer problem solving is adequate), closed system thinking (i.e. the environment only contributes constraints for problem solving), determinism (i.e. we can predict the future as well as causal relationships), and positivism (i.e. enterprises and technologies have an existence that is independent of people).

The "Grand Challenges" as well as the useful approaches for coping that we have discussed bring into question the adequacy of traditional assumptions. Moreover, they propose some new assumptions such as holism, open systems thinking, construtivism and indeterminism. These assumptions require the EA field to revisit the meaning of many important and core concepts such as the meaning of enterprises (i.e. object) as systems, the meaning of designing enterprises (subject) and the meaning of being a designer (i.e. actor) of enterprises.

A first step in the right direction of redefining the meaning of EA is to literally look outside the box or adopt a new paradigm about enterprises and their construction, design and operation. Many insightful contributions in the fields of organizational communication, design, organizational sciences and information systems may offer possible paths towards answers. Some of the promising contributions are the Semantic Turn (ST) [62], Design Thinking (DT) [63], Social Shaping of Technology (SSOT) [64], Organizational Innovation [65], and Scientific revolutions [66].

DT acknowledges the context of a problem and employs alternative and creative approaches to generate solutions. Insights from works such as Thomas Kuhn's The structure of Scientific Revolutions [66] about paradigm thinking and allowing for paradigm shifts should be relevant. A paradigm shift implies identifying and challenging the basic assumptions accepted as status quo and accepting alternatives.

The ST offers insights in the implication of considering meaning as an important dimension when considering and designing artifacts; enterprise architecture and it related technologies (e.g. models, theories, frameworks, etc.) are artifacts. Similarly to ST, the model of SSOT (and the related topic of sociomateriality [67]) is concerned with the meaning and social dimension of technologies. As such the model offers insights into how people understand, adapt and use technologies as well as how social forces play a role in defining technologies.

The field of organization innovation offers a wealth of theories and models for understanding what innovation is in the context of organizations and what factors hinder and foster it.

Over the last decade, faced with the inability of traditional EA approaches to cope with the realities of modern organizations, a number of research initiatives have started to lay the corners of new EA paradigms. In their quest for redefining EA, many of them have looked beyond the traditional EA boundaries of software and systems engineering as well as Taylorist influenced management literature. As proposed by Lapalme [18], two alternatives streams to traditional EA, which we will call Enterprise IT Architecture, seem to be emerging.

The first alternative stream, to our knowledge, doesn't go by any specific label. Lapalme [18] has tentatively proposed the label of "Enterprise Integration" because many of the contributions to this stream are concerned with integrating the various dimensions of the enterprise. Within this stream, there is no official consensus about the meaning of EA, however, in essence, most adhere to the principles that enterprises must be designed in a holistic manner that is informed by systems thinking. Typically, a key objective is to foster coherency within the organizations across structures in order to facilitate the execution of business strategies and change initiatives. Another recurring theme within this stream is the advocacy that the IT dimension of an enterprise is one of many that must be designed and integrated with the others. Examples of contributors to this alternative stream are Bernus et al [68], Giachetti [24], EARF [20], Doucet et al [69], and Rebovich \& White [44].

Giachetti [24] argues that EE is multi-disciplinary in nature, requiring knowledge from systems engineering and other root disciplines (industrial engineering, organisation sciences, psychology, sociology, information sciences, and management sciences). He offers an enterprise engineering methodology (demonstrating principles, models, methods, and tools) for designing the entire enterprise from its initial conceptualization to its final design.

The second alternative stream, to our knowledge doesn't go by any specific label, too. Lapalme [18] has tentatively proposed the label of Enterprise Ecological Adaptation because many of the contributions to this stream are concerned with fostering the capacity for innovation and adaptation within the enterprise as a means to cope with complexity and uncertainty within and without of organizations. For the moment, this is a very eclectic stream, hence it is difficult to identify a specific recurring theme. However, contributors to this stream are often concerned with enterprise-environment coevolution, the design of dialogues and the empowerment of people. Examples of contributors to this alternative stream are Lapalme and de Guerre [52], Dietz et al. [23], Taylor [70], Gharajedaghi [71] and Graves [46].

Gharajedaghi [71] suggests an interactive design approach in defining enterprise problems and designing solutions after defining the enterprise as a system but emphasising the need to understand system principles that govern enterprise evolution.

Recently, the Federation of Enterprise Architecture Professional Organizations, a federation of 17 international organizations representing different aspects of EA, published a common perspective on the meaning of EA [72]. The paper acknowledges that the field of EA is shifting from traditional EA with a focus on IT to a more holistic approach (the first alternative stream). Moreover, the paper acknowledges that EA could be a means for fostering innovation, the second alternative stream. Consequently, the paper is evidence that 
the professional portion of the EA community is also engaged an exploring the redefinition of EA and seems to be converging within the research community.

\subsection{Summary}

As discussed, a number of advances in the field of EA have been made with regards to the "Grand Challenges". Given space limitations, as stated previously, the intent was not to present an exhaustive review of contributions. However, we would like to point-out a couple of important ideas. Firstly, various non-technical domains have to contribute to the advancement of EA. Secondly, advances based on the insights of systems thinking and complexity sciences are not rare. However, most contributions focus on the streams of hard systems and dynamics systems thinking. Little has been done with regards to the other streams. Thirdly, to our knowledge, there exist no significant advances in EA with regards to coping with the new realities of enterprises (eg. virtuality, bounderyless, cultural heterogeneity and knowledge retention). Fourthly, many of the discussed advances are still very preliminary.

\section{FUTURISTIC SCENARIOS FOR ENTERPRISE ARCHITECTURE}

In the previous sections we have discussed the "Grand Challenges" that we believe will be relevant to the EA community for the foreseeable future as well as current advances and possible paths for further investigation. Indirectly, we have touched upon possible future scenario for the field of EA and EE. This section presents, given the context of the ideas presented in the previous sections, possible futuristic scenarios for EA as both a research field and possible profession.

\subsection{Scenarios for enterprise architecture research}

\subsubsection{Widening scope of theoretical influences}

As stated previously, the original influences of EA are software and systems engineering. Mostly guided by system thinking, alternative EA streams have emerged. Beyond the influences of systems thinking, which is itself a very multidisciplinary topic, fields such as sociology, psychology, organizational studies and anthropology have influenced many of the contributions in the alternative EA streams. There is strong evidence that this widening of scope of theoretical influences will continue.

\subsubsection{Solidifying theoretical foundations}

The field of EA emerged mostly out of the trenches of practicum, hence informed by the experiences of software and systems engineering practitioners that naturally tried to transfer the theories and models of their field to the emerging concerns of EA. Consequently, historically, EA as a field wasn't built on scientifically tested foundations.

Over the last decade, researchers have started building theoretical foundations for EA. One could expect that over the coming decade, as our understanding of the nature of enterprises advances and insights from other fields are transferred, the theoretical foundations for EA will grow.

\subsubsection{Development of tested technologies}

Many technologies (methods, tool and techniques) have been developed over the years for guiding the practice of EA. However, there is little evidence that these technologies have been proven to be effective. Moreover, most of the currently available technologies for undertaking EA are oriented towards traditional EA. One would expect that novel technologies would be designed and validated for undertaking EA according to the alternative streams.

\subsection{Scenarios for the enterprise profession}

\subsubsection{Evolution of the profession}

The evolution of the profession of EA is linked to the development of different frameworks after the initial Zachman framework was introduced. Currently TOGAF offers certification with more than 40000 certified architects. However, even though TOGAF may be dominant as a market leader, the theoretical foundation of TOGAF is lacking, as discussed in Gerber, Kotze \& Van der Merwe [73] where they identified inconsistencies with the TOGAF 9 Architecture Content Framework.

In many countries it is difficult to establish the need of enterprise architects due to the classification of the job ranging from Programmer Analyst to Business Analyst. In futuristic scenarios the awareness of different types of enterprise architect should be more prominent and more appropriate naming conventions emerge as the market seeks the skill set provided by enterprise architects in specific streams of 'doing' EA.

\subsubsection{Evolution of formal education}

On the educational front EA has been included in the ACM/AIS 2010 Information Systems curriculum [74] as one of the high-level outcome expectations. However, teaching EA is a challenge due to the level of strategic thinking required that influences the teaching thereof. Currently EA is mostly taught in postgraduate courses where the learners are often more mature and understand the complexity of EA. In future scenarios, the educators will have to rethink the role that they can play in equipping the students to be ready for the rapid technological changes experienced in the complex organization. In the next decade the field of EA will mature and as in any young discipline, more clarity will emerge on what is expected from an enterprise architect. This will influence the teaching in undergraduate courses to include not only specialized skills such as modeling, but also to provide the fundamental knowledge for graduates to act as enterprise architects.

\section{CONCLUSION}

As discussed, the challenges that will confound organizations of the future will not be in short supply. Beyond being numerous, these challenges, if not addressed, will have the power to bring even the largest of organizations to their knees as we have already started to witness with the near bankruptcy of General Motors and the near collapse of Greece and others governments.

The field of EA has the potential to offer significant insights and technologies for helping organization to address 
the "Grand Challenges" of the future. However, in order to be capable of such a feat, the field of EA must continue to mature as well as reinvent itself.

By 2025 , we believe that EA as a field and profession will be on much firmer ground and will have established a body of knowledge that scientifically demonstrates its capacity to help enterprises face the world of tomorrow.

The combined need for defining solutions for new challenges and the necessary to evolve the field of EA offers fruitful grounds for innovative research. Further research should be guided by the following objectives:

- Push the boundaries of the field through promoting a multidisciplinary approach. Enterprise architecture as a field must avoid being or becoming isolated; hence no recognizing the value of the insights from other fields.

- Focus on strengthening the theoretical roots of the field through the development theories and models that are scientifically sound;

- Value the design of EA technologies that are effective, pragmatic and accessible to key enterprise stakeholders.

As highlighted in section 3 and 4, there are a number of research questions and topics that should be investigated in future research initiatives. The key questions to be investigated include:

- How do we achieve socially and environmentally responsible, humane enterprise architecture that focus on creating systems for smart people?

- How do we do enterprise architecture in the context of increasing complexity?

- How do we do enterprise architecture when we can no longer act "as if" we can understand the "whole picture and predict the future?

- How can enterprise architecture contribute to the design of non-traditional organizations?

- How can enterprise architecture contribute to addressing the new realities of organizations?

- How must enterprise architecture redefine itself in order to stay relevant?

A great deal of current EA focuses on modeling and planning concerns. Given that EA should strive to be more considerate of people, society and the environment as well as contribute to the development of organization capacity for sense-making and innovation, new research topics emerge that are of importance and should be pursed, including:

- The design of dialogues between heterogeneous stakeholders;

- The inclusion of innovation-centric concerns within EA technologies and practices.

- The implications for EA of systems thinking stream such as soft systems, critical systems and post-modern systems thinking.

In summary, since EA is concerned with the design of sustainable organizations for the future, then doing and advancing EA will be a "Grand Challenge" for today and the foreseeable future.

\section{REFERENCES}

[1] IBM, "IBM Unveils 5 Smart Technology Trends For The Next 5 Years," 2013. [Online]. Available:

http://www.forbes.com/sites/gregsatell/2013/12/17/ibmunveils-5-smart-technology-trends-for-the-next-5-years/.

[2] Gartner, "Gartner Identifies the Top 10 Strategic Technology Trends for 2014," 2013. [Online]. Available: http://www.gartner.com/newsroom/id/2603623.

[3] Accenture, "Accenture Techmology Vision 2014 Report," 2013. [Online]. Available:

http://www.accenture.com/microsites/it-technologytrends-2014/Pages/tech-vision-report.aspx.

[4] IEEE Computer Society, "Top Technology Trends for 2014," 2013. [Online]. Available:

http://www.computer.org/portal/web/membership/Top-10Tech-Trends-in-2014.

[5] J. A. Zachman, "The Zachman Framework for Enterprise Architecture." Zachman International: http://www.zachman.com/, 2011.

[6] J. Schekkerman, How to survive in the jungle of enterprise architecture frameworks, 2nd edition, 2nd Editio. Trafford Publishing, Victoria, 2004.

[7] J. A. Zachman, "A framework for information systems architecture,” IBM Syst. J., vol. 26(3), pp. 276-292, 1987.

[8] Charles J. Petrie, Ed., Enterprise integration modeling. MIT Press., 1992.

[9] PERA, "PERA enterprise integration web site." [Online]. Available: http://pera.net. [Accessed: 15-Jan-2015].

[10] M. Kosanke, K., Zelm, "CIMOSA - about us.” [Online]. Available: http://www.cimosa.de/About_us.htm.

[Accessed: 15-Jan-2015].

[11] D. Chen, B. Vallespir, and G. Doumeingts, "GRAI integrated methodology and its mapping onto generic enterprise reference architecture and methodology," Comput. Ind., vol. 33, no. 2, pp. 387-394, 1997.

[12] G. Doumeingts, B. Vallespir, M. Zanettin, and D. Chen, "GIM, GRAI integrated methodology: A methodology for designing CIM systems, version 1.0.” France: University of Bordeaux, 1992.

[13] ISO/IEC, "ISO/IEC/IEEE 42010 Systems and Software Engineering - Architecture Description." ISO/IEC, 2011. M. de Vries, A. Gerber, and A. Van der Merwe, "The Nature of the Enterprise Engineering Discipline," Lect. Notes Bus. Inf. Process. - Proc. EEWC 2014 - 4th Enterp. Eng. Work. Conf., vol. 174, pp. 1-15, 2014.

[15] L. Kappelman, The SIM guide to enterprise architecture. Boca Raton: CRC Press., 2011.

[16] J. Lapalme, "Three Schools of Thought on Enterprise Architecture," IT Prof., vol. 14, no. 6, pp. 37-43, Nov. 2012.

[17] F. Theuerkron, Lightweight Enterprise Architecture. CRC Press, 2005.

[18] J. Lapalme, "Three Schools of Thought on Enterprise Architecture," IT Prof., vol. 14, no. 6, pp. 37-43, Nov. 2012.

[19] J. W. Ross, P. Weill, and D. Robertson, Enterprise Architecture as Strategy: Creating a Foudnation for Business Execution. Harvard Business Press, 2006.

[20] EARF, "EARF - EA Definition," 2012. .

[21] J. Lapalme and D. de Guerre, "An Open Socio-Technical Systems Approach to Enterprise Architecture," in Beyond Alignment: Applying Systems Thinking to Architecting Enterprises, 1st ed., vol. 2, no. 3, J. Gøtze and A. JensenWaud, Eds. London: College Publications, 2013.

[22] J. A. P. Hoogervorst, Enterprise governance and enterprise engineering. Springer, 2009. 
[23] J. L. G. Dietz, J. A. P. Hoogervorst, A. Albani, D. Aveiro, E. Babkin, J. Barjis, A. Caetano, P. Huysmans, J. Iijima, S. J. H. Van Kervel, H. Mulder, M. Op, H. A. Proper, J. Sanz, L. Terlouw, J. Tribolet, J. Verelst, and R. Winter, "The discipline of enterprise engineering," Int. J. Organ. Des. Eng., vol. 3, no. 1, pp. 86-114, 2013.

[24] R. E. Giachetti, Design of Enterprise Systems: Theory, Architecture, and Methods. CRC Press, 2011, p. 447.

[25] J. L. G. Dietz, Enterprise Ontology. Springer, 2006.

[26] J. L. G. Dietz and J. A. P. Hoogervorst, "Enterprise ontology in enterprise engineering," in Proceedings of the 2008 ACM symposium on Applied computing - SAC '08, 2008, p. 572.

[27] D. L. Olson and S. Kesharwani, Enterprise Information Systems: Contemporary Trends and Issues. World Scientific, 2010.

[28] J. A. Zachman, "The Zachman Framework for Enterprise Architecture." p. 2011, 2011.

[29] John A. Zachman, "About the Zachman Framework," 2008. [Online]. Available:

http://www.zachman.com/about-the-zachman-framework

[30] John A. Zachman, "About the Zachman Framework," 2008 .

[31] J. A. Zachman, "The Zachman Framework For Enterprise Architecture. A Primer for Enterprise Engineering and Manufacturing." 2003.

[32] M. W. Maier, The Art of Systems Architecting, 3rd ed. CRC Press, 2011

[33] E. Ostrom, "Crossing the great divide: coproduction, synergy and development," World Dev., vol. 24, no. 6, pp. 1073-1087, 1996.

[34] A. P. Picot, R. Reichwald, and R. Wigand, "People in the Boundaryless Organization: New Demands on Employees and Managers," in Information, Organization and Management, Springer Berlin Heidelberg, 2008, pp. 369421.

[35] R. Ramírez, J. W. Selsky, and K. van der Heijden, Eds., Business Planning in Turbulent Times: new methods for applying scenarios, 2nd ed. Routledge, 2010.

[36] E. Trist, “, Referent Organizations and the Development of Inter-Organizational Domains," Hum. Relations, vol. 36, pp. 269-284, 1983.

[37] W. R. Ashby, An introduction to cybernetics. Chapman \& Hall, 1956.

[38] G. Satell, "Managing For Disruption,” 2014. [Online]. Available:

http://www.creativitypost.com/business/managing_for_dis ruption.

[39] R. Villarreal, "Enterprise Architecture of Sustainable Development: An Analytical Framework," in A Systemic Perspective to Managing Complexity with Enterprise Architecture, P. Saha, Ed. IGI Global, 2013.

[40] M. Luoma, "A Play of Four Arenas: How Complexity Can Serve Management Development," Manag. Learn., vol. 37, pp. 101-123, 2006.

[41] C. F. Kurtz and D. J. Snowden, "The new dynamics of strategy: Sense-making in a complex and complicated world," IBM Syst. J., vol. 42, no. 3, pp. 462-483, 2003.

[42] M. C. Jackson, "Fifty years of systems thinking for management," J. Oper. Res. Soc., vol. 60, no. 1, pp. 24 32, 2009.

[43] M. Emery, "The current version of Emery's open systems theory," Syst. Pract. Action Res., vol. 13, no. 5, pp. 685703, 2000.

[44] G. Rebovich and B. E. White, Eds., Enterprise Systems Engineering: Advances in the Theory and Practice. CRC Press., 2010.
[45] T. Graves, Mapping the enterprise: modelling the enterprise as services with the Enterprise Canvas. Tetradian Books, 2010.

[46] T. Graves, Real Enterprise-Architecture Beyond IT to the whole enterprise. Colchester: Tetradian Books, 2008.

[47] P. Saha, A Systemic Perspective to Managing Complexity with Enterprise Architecture. IGI Global, 2013.

[48] M. C. Jackson, "Creative Holism: A Critical Systems Approach to Complex Problem Situations, Systems Research and Behavioral Science Title," Syst. Res. Behav. Sci., vol. 2, no. 5, pp. 647-657, 2006.

[49] S. Beer, Brain of the Firm. Penguin Press, 1972.

[50] J. John Gøtze and A. Jensen-Waud, Eds., Beyond Alignment: Applying Systems Thinking in Architecting Enterprises Title. College Publications, 2013.

[51] J. Forrester, "Counterintuitive behavior of social systems," Technol. Rev., vol. 73, no. 3, pp. 52-68, 1971.

[52] J. Lapalme and D. de Guerre, "Enterprise-in-Environment Adaptation - Enterprise Architecture and Complexity Management," in A Systemic Perspective to Managing Complexity with Enterprise Architecture, 1st ed., P. Saha, Ed. IGI Global, 2013.

[53] J. A. Zachman, "The Zachman Framework: What Experts Have Not Yet Perceived." 2009.

[54] J. A. Zachman, "Enterprise Architecture: The Issue of the Century," Database Program. Des. Mag., 1996.

[55] R. G. McGrath, The End of Competitive Advantage: How to Keep Your Strategy Moving as Fast as Your Business. Harvard Business Review Press, 2013.

[56] National Intelligence Council, "Global Trends 2030: Alternative Worlds," 2012.

[57] K. Vicente, The human factor: Revolutionizing the way people live with technology. Routledge, 2003.

[58] W. Ulrich and M. Reynolds, "Critical systems heuristics," in Systems Approaches to Managing Change: A Practical Guide, M. Reynolds and S. Holwell, Eds. Springer, 2010.

[59] W. K. Michener, T. J. Baerwald, P. Firth, J. L. Parlmer, Margaret A. Rosenberger, and H. Sandlin, Elizabeth A. Zimmerman, "Defining and Unraveling Biocomplexity," Bioscience, vol. 51, no. 12, pp. 1018-1023, 2001.

[60] L. M. Camarinha-Matos and H. Afsarmanesh, "Brief Historical Perspective for Virtual Organizations," in Virtual Organizations, L. M. Camarinha-Matos, H. Afsarmanesh, and M. Ollus, Eds. Springer, 2005.

[61] L. Laverdure, A. Conn, J. W. Ross, and C. M. Beath, "Enterprise Architecture," Architecture, vol. 8, no. 1, 2012.

[62] K. Krippendorff, The Semantic Turn: A New Foundation for Design. CRC Press, 2006.

[63] N. Cross, Design Thinking. Bloomsbury Academic, 2011.

[64] W. J. Orlikowski, "The Duality of Technology: Rethinking the Concept of Technology in Organizations," Organ. Sci., vol. 3, no. 3, pp. 398-427, 1992.

[65] F. Damanpour, "Organizational Innovation: A MetaAnalysis of Effects of Determinants and Moderators," Acad. Manag. J., vol. 34, no. 3, pp. pp. 555-590, 1991.

[66] T. S. Kuhn, The Structure of Scientific Revolutions: 50th Anniversary Edition. University Of Chicago Press; Fourth Edition edition, 2012.

[67] P. M. Leonardi, "Theoretical Foundations for the Study of Sociomateriality," Inf. Organ., vol. 23, no. 2, pp. 59-75, 2013.

[68] P. Bernus, L. Nemes, and G. Schmidt, Handbook on enterprise architecture. Springer Berlin / Heidelberg, 2003. 
[69] G. Doucet, J. Gotze, P. Saha, and S. Bernard, Coherency Management. International Enterprise Architecture Institute, 2009.

[70] P. R. Taylor, "Enterprise Architecture's Identity Crisis: New Approaches to Complexity for a Maturing Discipline," in A Systemic Perspective to Managing Complexity with Enterprise Architecture, P. Saha, Ed. IGI Global, 2013.

[71] J. Gharajedaghi, Systems thinking - managing chaos and complexity: a platform for designing business architecture. New York: Elsevier Inc., 2006.

[72] FEAPO, "The FEAPO Enterprise Architecture Perspective Initiative: A Common Perspective on Enterprise Architecture," Archit. Gov. Mag., vol. 9, no. 4, pp. 11-17, 2013.

[73] A. Gerber, A. Van der Merwe, and P. Kotze, "Towards the Formalisation of the TOGAF Contenet Metamodel using Ontlogies," in The 12th International Conference on Enterprise Information Systems, 2010.

[74] J. I. 2010 C. T. Force, "ACM / AIS Curriculum," $A C M$ and AIS, 2010.

James Lapalme is an Assistant Professor in Software and IT engineering at the Ecole de technologie superieure, Canada. His main research interests are enterprise architecture \& engineering, information systems design, and the design of technologies for supporting innovation. He is an author of papers published in international journals and conference proceedings, and he is a referee for international journals.

Aurona Gerber is a principal researcher in the Center for Al Research of CSIR Meraka in South Africa and the University of Pretoria. She is the present chair of the South African IEEE SMCS Chapter, as well as a founding member of the South African Chapter of the AIS. Internationally she is a founding member and co-chair of the IEEE Enterprise Engineering and Enterprise Architecture Technical Committee. Her current research is in the use and design of advanced modelling, ontologies and intelligent systems in various domains such as enterprise architecture and biodiversity informatics.

Alta van der Merwe is Head of Department, Informatics at the University of Pretoria. She is the founder and past chair of the South African IEEE SMCS Chapter, specialist editor of the SAIEE journal (Software Engineering track) and co-founder and past chair of the Enterprise Architecture Research Forum. Internationally she was involved in the proposal and acceptance of the Open Group Academic Forum and also the IEEE Enterprise Engineering and Enterprise Architecture Technical Committee, where she still acts as cochair. Prof van der Merwe focuses on research related to Enterprise Architecture, Data Analytics (Social media) and Design and Innovation. She is the current president of the South African Institute of Computer Scientists and Information Technologists (SAICSIT) where she has been involved in the establishment of the South African Computing Accreditation Board (SACAB).

John A. Zachman is the originator of the "Framework for Enterprise Architecture," also known as the Zachman ${ }^{\circledR}$ Framework, which has received broad acceptance around the world as an integrative framework, or "periodic table" of descriptive representations for Enterprises. Mr. Zachman serves on the Executive Council for Information Management and Technology (ECIMT) of the United States Government Accountability Office (GAO) and on the Advisory Board of the Data Administration Management Association International (DAMA-I) from whom he was awarded the 2002 Lifetime Achievement Award. He was awarded the 2009 Enterprise Architecture Professional Lifetime Achievement Award from the Center for Advancement of the Enterprise Architecture Profession as well as the 2004 Oakland University, Applied Technology in Business (ATIB), Award for IS Excellence and Innovation.

Knut Hinkelmann is a head of Master of Science in Business Information Systems at the University of Applied Sciences and Arts
Northwestern Switzerland FHNW. He holds a degree in Computer Science and made a PhD in deductive databases. He has been working at the German Research Center for Artificial Intelligence and was product manager at Insiders Information Management He joined FHNW in 2000 as a professor for Information Systems.

Marne de Vries is a senior lecturer at the Department of Industrial and Systems Engineering at the University of Pretoria. She holds a degree in Industrial Engineering and completed her $\mathrm{PhD}$ within the enterprise engineering discipline. She currently lectures on Information Systems Design and Enterprise Architecture. 